\title{
APPLICATION OF ELECTRICAL RESISTIVITY TOMOGRAPHY FOR MAPPING ZONES AFFECTED BY ROOF CAVING DURING TUNNEL CONSTRUCTION
}

DOI: http://dx.doi.org/10.18509/GBP.2020.01

UDC: 550.373:528.9]:624.191

\author{
Stefan Dimovski ${ }^{1}$ \\ Nikolay Stoyanov ${ }^{2}$ \\ University of Mining and Geology "St. Ivan Rilski" Faculty of Geoexploration, Bulgaria \\ ${ }^{1}$ Department of Applied Geophysics \\ ${ }^{2}$ Department of Hydrogeology and Engineering Geology
}

\begin{abstract}
The process of tunnel construction, for various reasons, is occasionally accompanied by emergency situations caused by roof caving. In these cases, the correct information for the spatial boundaries and the geometry of the collapsed and loosened areas in the problematic region is of great importance for the effective reinforcement of the disturbed rock mass. The proposed geophysical approach for three-dimensional mapping of these areas is based on the application of electrical resistivity tomography. The possibilities for detailed delineation of the fractured zones in the area above the tunnel structures according to electrical resistivity are studied. This approach is tested in the process of mapping the subsurface space in an area where roof caving occurred in one of the tunnels under construction along the Struma motorway in South-West Bulgaria. The presented results confirm the high engineering efficiency of the proposed approach for data acquiring, analysis and interpretation.
\end{abstract}

Keywords: geophysical surveying, ERT method, tunnel construction, roof caving, disturbed rock mass

\section{INTRODUCTION}

The geophysical non-invasive techniques are frequently used in the study of near-surface section in areas where emergencies, caused by roof caving or other geodynamic processes during the construction or operation of underground facilities, have happened. Their application is not only the most effective approach but sometimes is the single possible method for recording the occurred changes in the geological environment and finding constructive solutions for the effective reinforcement of the disturbed rock mass. Particularly productive in these cases is the method of electrical resistivity tomography (ERT), which in the last decade has a wide application in Bulgaria for solving different geological, mining, hydrogeological, engineering and environmental problems [1], [2], [3], [4], [5], [6], [7], [8], [9], [10], [11]. Its efficiency is determined by the possibility for good differentiation of rocks, their secondary alterations and degree of water saturation according to the specific electrical resistivity, and more precisely by the scale in which ionic conductivity is manifested [4], [6], [7].

A specific example demonstrates the capabilities of the ERT method for studying the geological section and mapping the spatial boundaries and geometry of the collapsed, loosened and disturbed zones in an area where roof caving occurred in one of the tunnels under construction along the Struma motorway in South-West Bulgaria. Subject of study 
is the subsidence caused by local collapse during construction in 2015 above tunnel "T1 - Blatino", part of the Highway "Struma" project, LOT 2, section "Dupnitsa Blagoevgrad" (Figure 1). The tunnel consists of two tubes and is constructed after the New Austrian Tunneling Method (NATM).

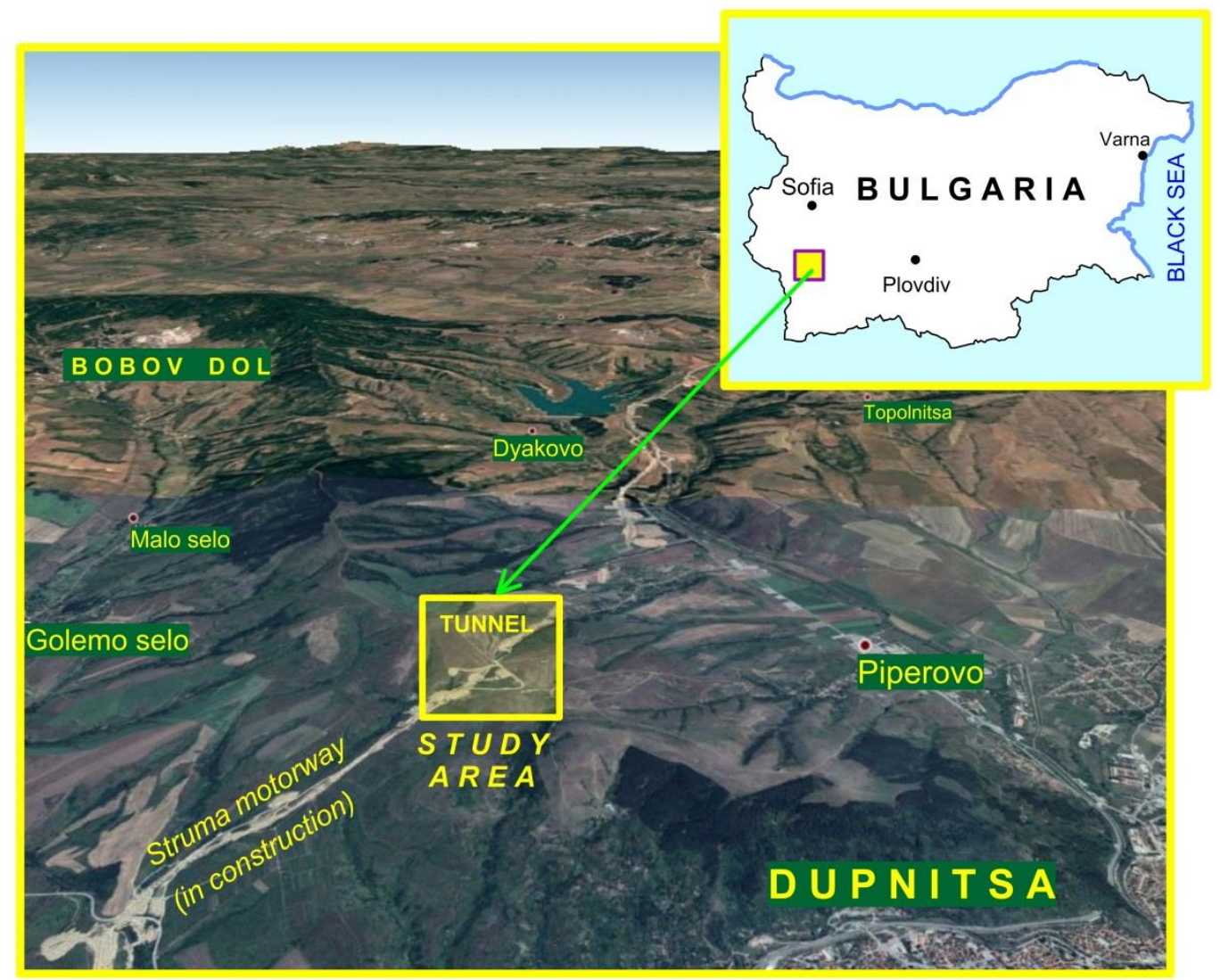

Figure 1. Location of the study area - tunnel "T1 - Blatino", part of the of Struma motorway, South-West Bulgaria

Diorites are dominant in the geological structure of the region. In the surface part of the section, down to a depth of 6-7 m, the rocks are very heavily weathered, completely fragmented and decomposed to clay. Underneath these materials, completely to moderately weathered diorites are uncovered. They are cracked and disintegrated to rock fragments of $10-20 \mathrm{~cm}$ in size, with a sandy-clay filler. The thickness of this weathered zone varies from $5-10 \mathrm{~m}$ up to $30 \mathrm{~m}$ or more. The underlying rocks are less weathered, the size of the rock fragments reaches $40 \mathrm{~cm}$ and the filler is sandy.

The main objective of the performed ERT study is to identify and map the spatial boundaries of: (1) Collapsed and loosened zones in the rock mass formed as a result of the roof caving that occurred during the excavation of the right tunnel tube; (2) Geologically fractured and disturbed zones above those parts of the two tunnel tubes that have not been excavated until the accident.

\section{METHODS AND INSTRUMENTS}

The applied ERT method is appropriate for two-dimensional mapping of the near-surface area in vertical sections along the surveyed lines [12]. Field measurements were done using a large number of electrodes connected as a Wenner-Schlumberger array to a multi- 
core cable [13]. Two sets of 12 core cable were used with a $10 \mathrm{~m}$ electrode spacing (24 electrodes in total). The registration was accomplished with the help of the equipment Terrameter SAS 1000, manufactured by the Swedish company ABEM.

The measurements were performed along 17 lines having a total length of $3910 \mathrm{~m}$ (each surveying line with a length of $230 \mathrm{~m}$ ). To achieve maximum resolution in the process of mapping the collapsed and loosened zones in the roof caving area, 9 parallel lines were surveyed, located about $10 \mathrm{~m}$ apart. Another 5 lines were oriented along the axe of the tunnel tubes, and the additional 3 lines were positioned on the periphery of the first set of lines with the intention to enhance the picture. The exact location of all surveying lines in the segment from $\mathrm{km} \mathrm{324+500} \mathrm{to} \mathrm{km} 324+750$ is presented in Figure 2.

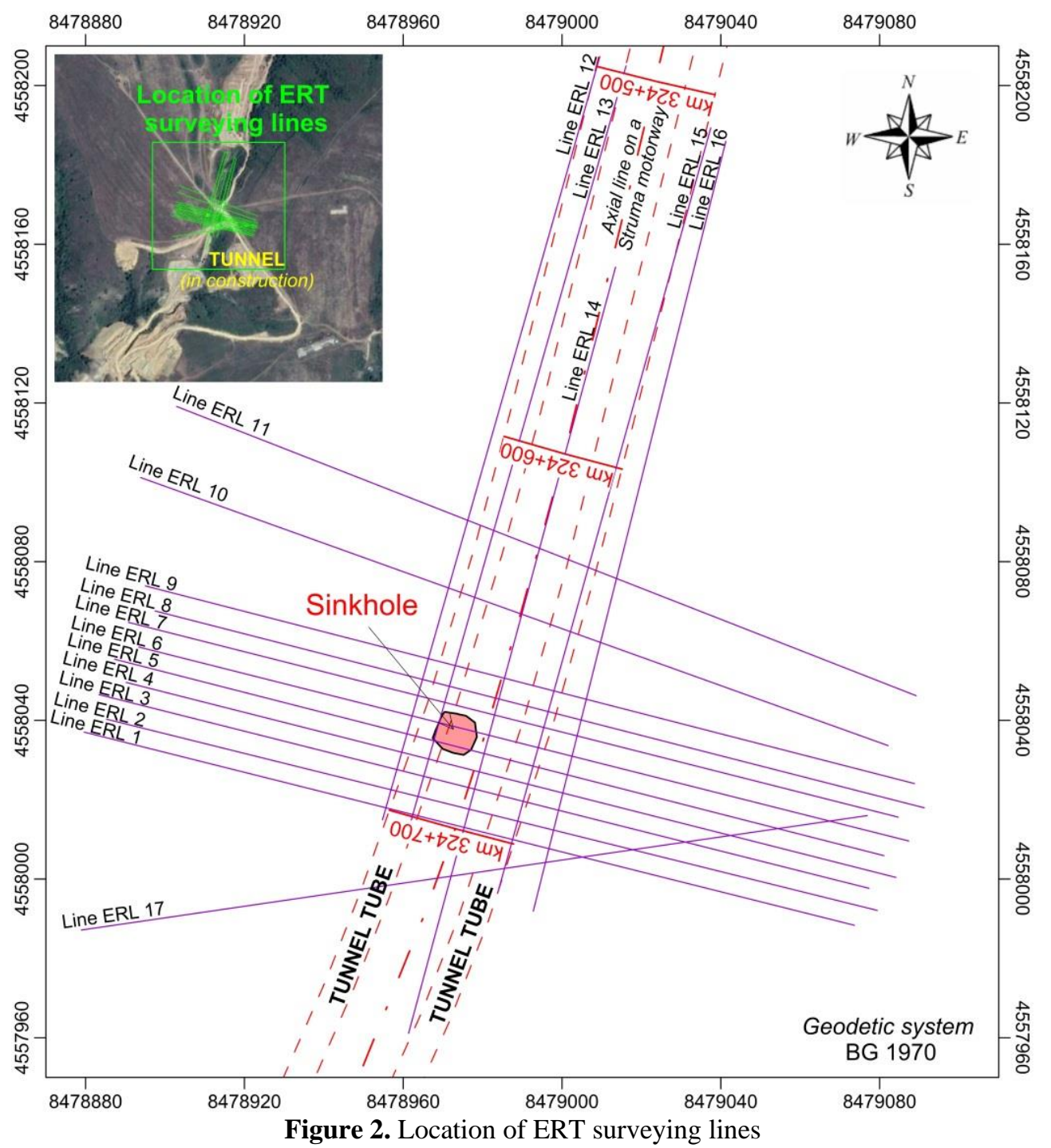

In the field data processing, the computer program RES2DINV [14] was used to obtain electrical resistivity sections along the 17 surveying lines. The so determined geoelectrical models were transformed into geological ones on the base of: (1) General information about the specific geological conditions in the area and the construction technology [4], [5]; (2) Reference data for the electrical resistivity of different rock types [15],[16]; (3) Data from the drilled boreholes [4], [7], [8]. 


\section{RESULTS AND INTERPRETATION}

The electrical resistivity distribution along the 17 studied lines obtained with the RES2DINV program is presented in Figure 3.
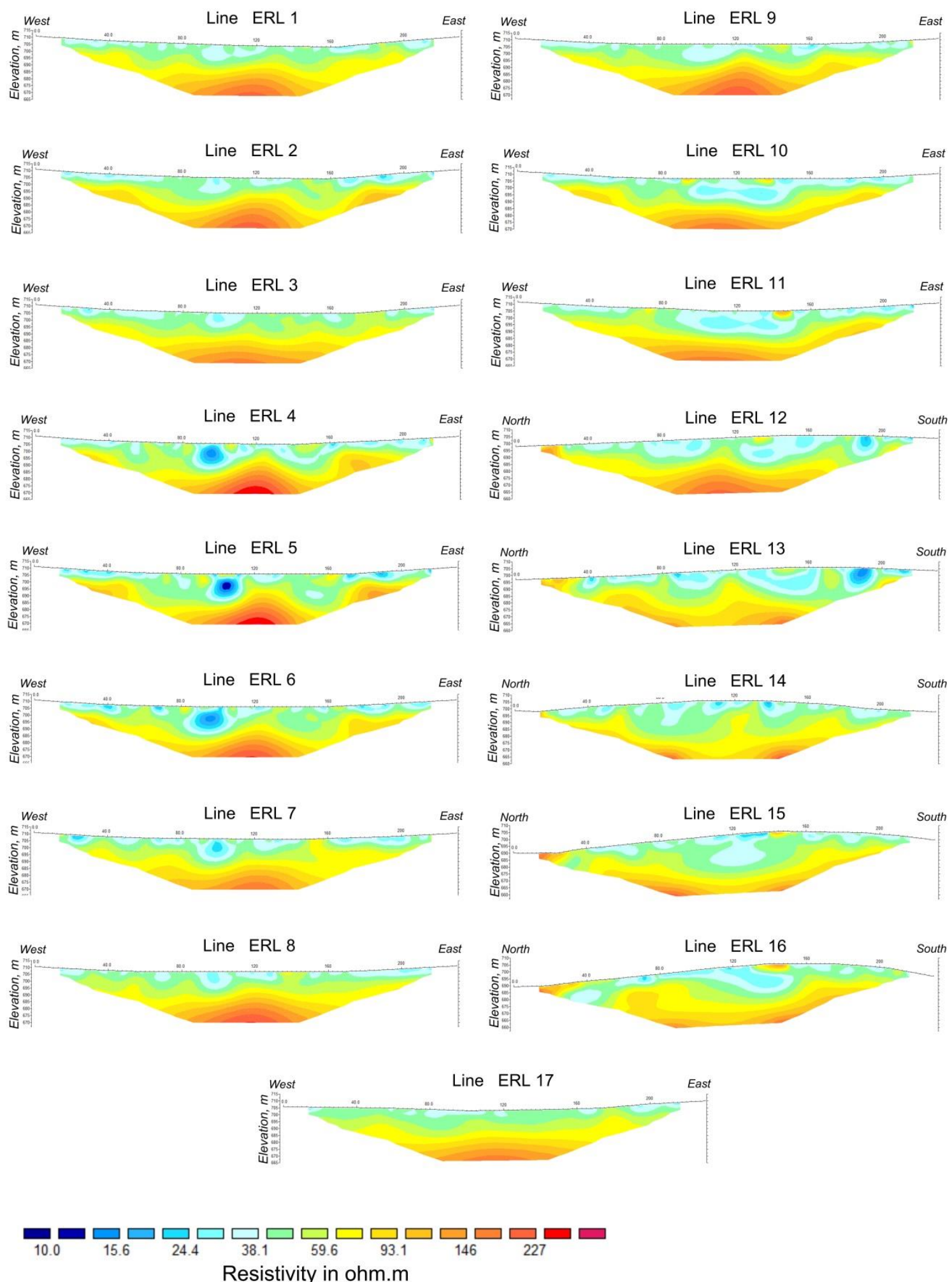

Figure 3. Electrical resistivity sections along the 17 surveying lines 
The complex analysis of geoelectrical sections, taking into account the available information about the geological, engineering-geological, hydrogeological and technogenic conditions in the region of tunnel "T1 - Blatino", gives reason to make the following more important conclusions regarding the determination of collapsed, loosened, and disturbed zones in the rock massif:

- The geoelectrical section along all lines is consistent regarding the electrical resistivity distribution in depth.

- The electrical resistivity of the varieties that compose the studied part of the subsurface space changes in a relatively wide range - from $10 \Omega \mathrm{m}$ to $200 \Omega \mathrm{m}$ and more. The established resistivities do not correlate closely with the table values of this parameter for weathered diorites. This is not so much related to the degree of natural secondary alterations, but mainly to the formation of collapsed and loosened zones around the tunnel roof caving area, the presence of intensely jointed zones and the complete or very high water saturation in the disturbed zones.

- The lowest electrical resistivity values (less than $25 \Omega \mathrm{m}$ ) most probably mark the upper part of the collapsed zone down to a depth of 15-17 m. It is a highly disintegrated and well-saturated environment composed of highly weathered diorites, decomposed to clay and small rock fragments. At a greater depth, in the interval from 20 to $25 \mathrm{~m}$, the collapsed zone is characterized by higher values of electrical resistivity - from 25 to $40 \Omega \mathrm{m}$ and more. These values are typical for diorites disintegrated to larger drained rock fragments with sandy filler.

- The comparatively higher electrical resistivity values (25 to $35 \Omega \mathrm{m}$ ), registered along the periphery of the collapsed zone, denote the boundaries of the loosened zone in the rock mass down to a depth of 15-17 m. At depths down to 20-25 m, due to the presence of large rock fragments, the spread of this zone is likely to be outlined by an environment with values of electrical resistivity increasing from 35 to about $50 \Omega \mathrm{m}$ or more.

- The low electrical resistivity values ( 25 to $35 \Omega \mathrm{m}$ ), registered outside the roof caving area and the connected to it collapsed and loosened zones, most probably characterize the geologically fractured and disturbed zones in the upper part of the rock mass down to a depth of 10-15 $\mathrm{m}$ and more. In depth, the continuation of these zones is mapped by higher electrical resistivity values, increasing from 35 to $75 \Omega \mathrm{m}$. This is associated with the presence of larger rock fragments as a result of the lower degree of weathering of the rock mass.

Detailed maps of the electrical resistivity distribution at various depths have been composed in order to delineate the spatial boundaries of the collapsed and loosened zones around the roof caving area and the geologically fractured and disturbed zones above those parts of the two tunnel tubes that have not been excavated so far. The derived maps are illustrated in Figure 4.

Based on the compiled geoelectrical maps and according to the zoning criteria defined above, the following schematic maps were drawn:

(1) Schematic maps illustrating the spread of the collapsed and loosened zones in the rock mass formed as a result of the roof caving that occurred in the segment from $\mathrm{km}$ $324+669.1$ to $\mathrm{km} 324+680$ during the excavation of the right tube of tunnel "T1 Blatino" - Figure 5;

(2) Schematic maps illustrating the spread of geologically fractured and disturbed zones above those parts of the two tunnel tubes that have not been excavated until the accident - Figure 6. 


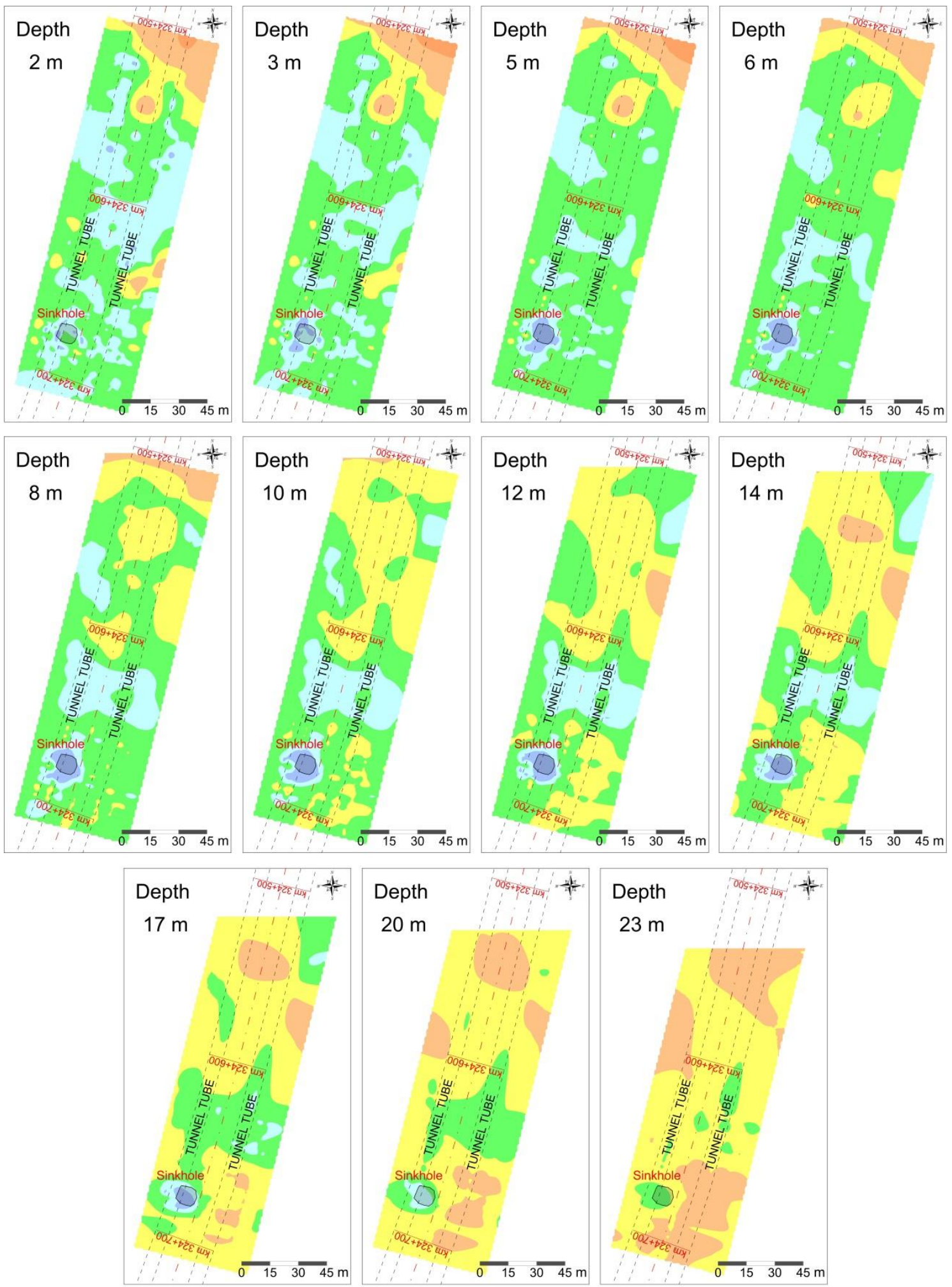

Resistivity in Ohm.m

$\begin{array}{llllll}10 & 25 & 35 & 50 & 75 & 150\end{array}$

Figure 4. Maps of the electrical resistivity distribution at various depths

in the region of tunnel "T1 - Blatino", segment from km 324+500 to km 324+750 


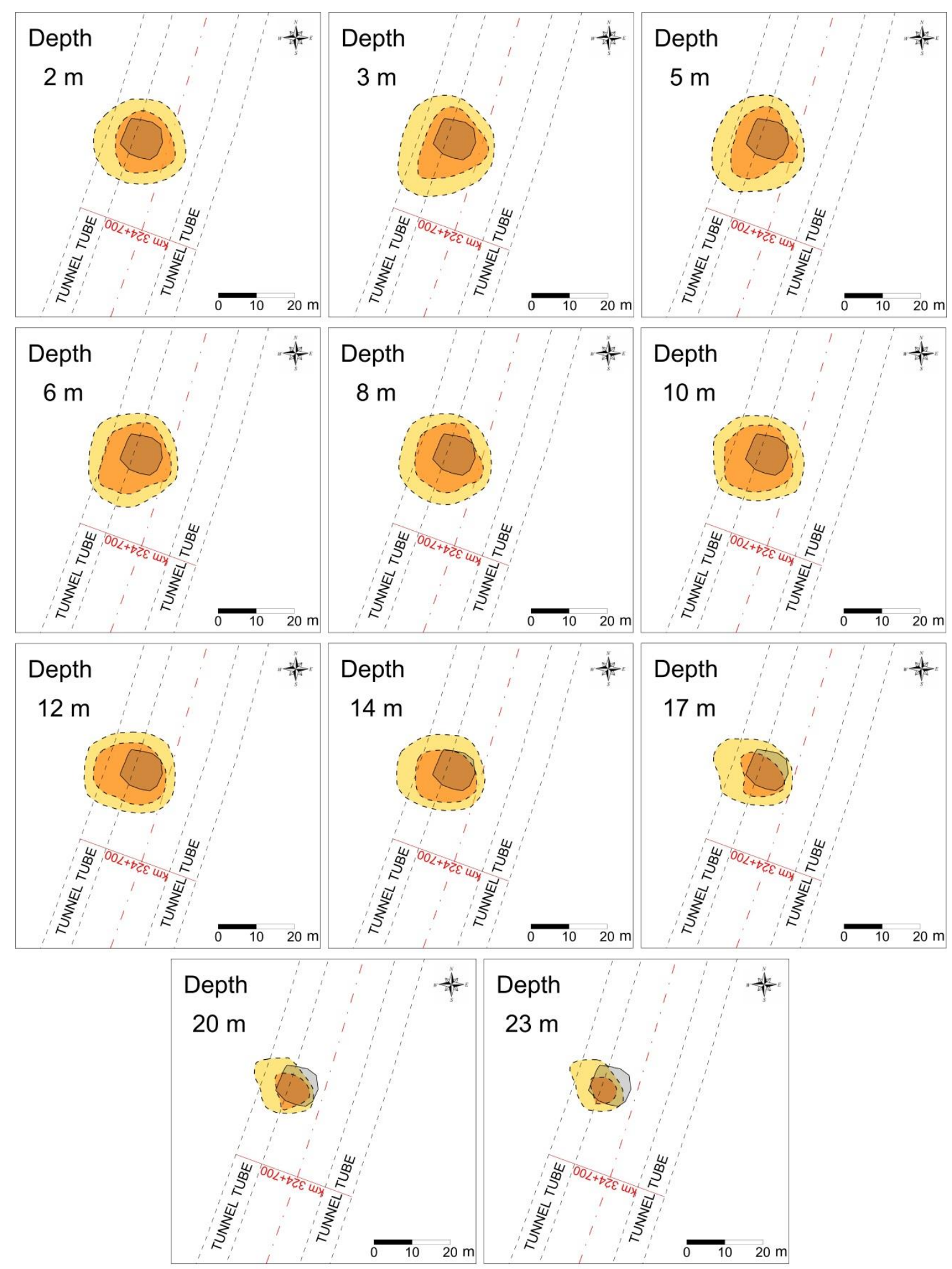

\section{- Collapsed zone}

Figure 5. Schematic maps illustrating the spread of the collapsed and loosened zones in the rock mass formed as a result of the roof caving in the segment from $\mathrm{km} 324+669.1$ to $\mathrm{km} \mathrm{324+680} \mathrm{-} \mathrm{right} \mathrm{tube} \mathrm{of} \mathrm{tunnel} \mathrm{"T1} \mathrm{-} \mathrm{Blatino"}$ 


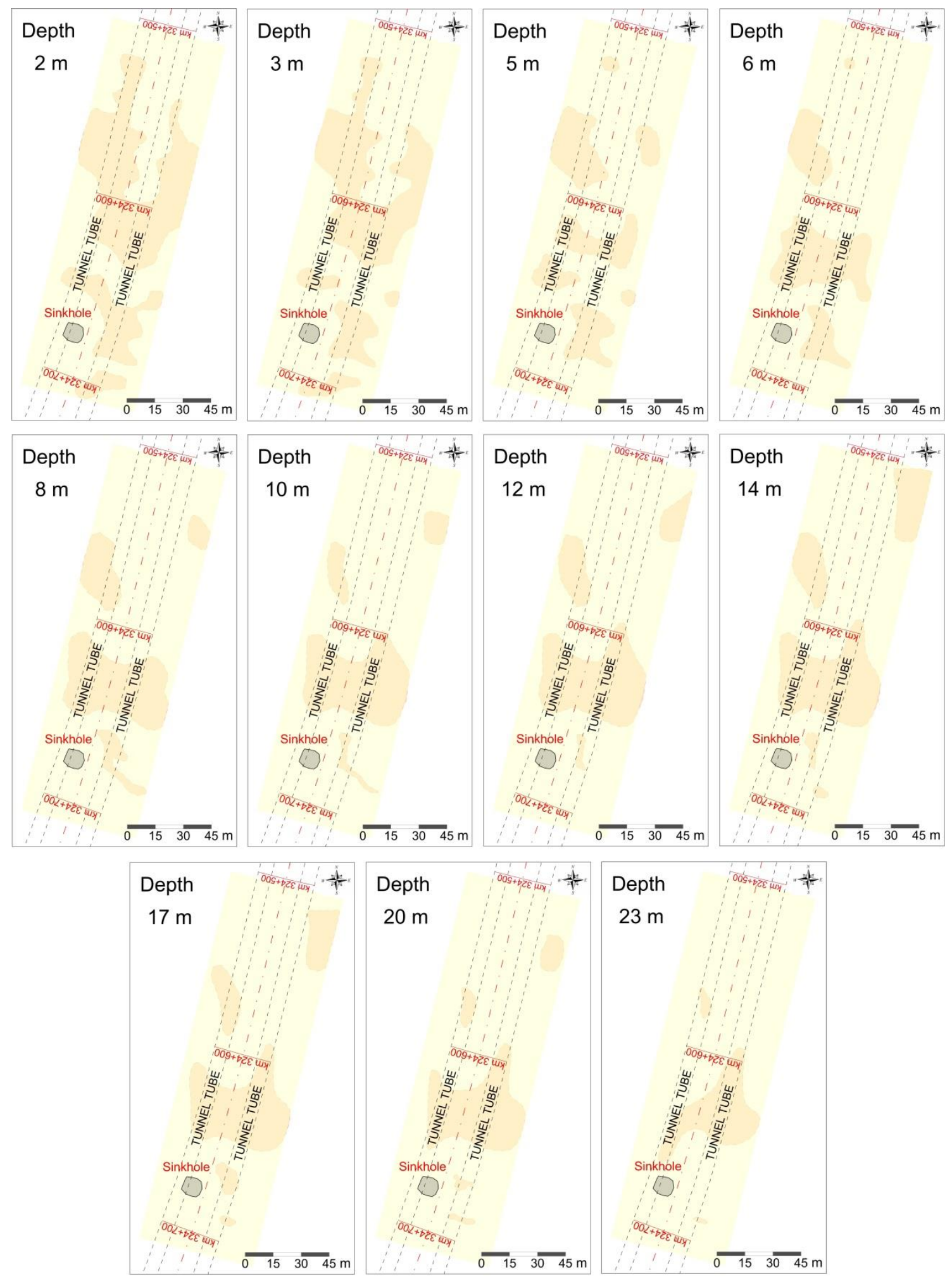

\section{- Sinkhole $\quad \square$ - Geologically fractured and disturbed zones}

Figure 6. Schematic maps illustrating the spread of geologically fractured and disturbed zones above those parts of the two tunnel tubes that have not been excavated until the accident 


\section{CONCLUSIONS}

The presented results confirm the high proficiency of the proposed geophysical approach, based on the application of electrical resistivity tomography, for three-dimensional mapping of the collapsed and loosened zones in the rock mass formed as a result of a roof caving that occurred in the process of tunnel construction. The acquired schematic maps were of great importance for the development of an applicable solution for the reinforcement of the disturbed rock mass. The geologically fractured and disturbed zones were also successfully delineated and taken into consideration during the remaining construction activities that have finished without an accident.

The proposed approach for data acquiring, analysis and interpretation can be used very effectively in the study of near-surface section in areas where emergencies, caused by roof caving or other geodynamic processes during the construction or operation of underground facilities, have happened.

\section{REFERENCES}

[1] Grigorova, M. \& Koprev, I. Geophysical investigations of "Starite kolibi" marble deposit in Central Southern Bulgaria, 5th International Scientific Conference GEOBALCANICA, Bulgaria, 2019, pp 37-42. DOI: 10.18509/GBP.2019.05

[2] Shanov, S., Mitev, A., Benderev, A., Kostov, K. \& Mihailova B. Electrical survey for detailed characterizing of underground karst: Example from Iskar River (Western Bulgaria). 5th Congress of Balkan Geophysical Society, Serbia, 2009.

[3] Grigorova, M. \& Koprev, I. Application of electrical resistivity tomography for sand underwater extraction, 4th International Scientific Conference GEOBALCANICA, North Macedonia, 2018, pp15-20. DOI: 10.18509/GBP.2018.02

[4] Dimovski, S., Stoyanov, N., Tzankov, C. \& Kisyov, A. A geophysical approach for mapping of abandoned mining workings and unconsolidated zones in coal mining areas, Journal of Mining and Geological Sciences, vol. 60, Part I, Geology and Geophysics, pp 99-103, 2017.

[5] Grigorova, M. \& Koprev, I. 3D model of limestone inclusions in Maritsa Iztok mine based on electrical resistivity tomography, Acta Geobalcanica, vol. 3 (2), pp.51-56, 2017. DOI: 10.18509/AGB.2017.06

[6] Dimovski, S., Stoyanov, N., Tzankov C. \& Kisyov, A. Application of electrical resistivity tomography for studying fissure-karst water-bearing complexes, 9th Congress of the Balkan Geophysical Society, Turkey, 2017, Paper 44018, 5 p. DOI: 10.3997/ 2214-4609.201702529

[7] Dimovski, S., Stoyanov, N., Kisyov, A. \& Yankova, M. Detection of zones characterized by different degree of water-saturation and mapping of landslide surfaces by application of electrical tomography, 7th Congress of the Balkan Geophysical Society, Albania, 2013, Paper 18504. 5 p. DOI: $10.3997 / 2214-4609.20131673$.

[8] Stoyanov, N., Trayanova, M., Dimovski, S. \& Benderev, A. Evaluation of the impact by deep artesian boreholes on fresh ground waters in the terrace of Kamchiya River, Geologica Balcanica, vol. 46 (2), pp 125-133, 2017.

[9] Kotsev, T., Kolev, S. \& Hristov, V. Modeling of groundwater flow and transport of pollutants caused by a difference in densities (on the example of the valley of Vulche dere creek, downstream of Eleshnitsa tailings pond). Engineering Geology and Hydrogeology, vol. 32, pp 3$12,2018$.

[10] Shanov, S., Vasilev, I., Mitev, A., Hristov, V. \& Mihailova, B. Electrical tomography for studies of the inner structure of dumps (Open-pit "Ellatzite", Bulgaria), 6th Congress of Balkan Geophysical Society, Hungary, 2011. 
[11] Georgieva, G., Kisyov, A., Tzankov, C., Shtirkova, B., Gourev, V. \& Ivanov, Y. Evaluation of geophysical methods for studying snowfields in Pirin Mountain, 10th Congress of the Balkan Geophysical Society, Bulgaria, 2019, Paper BGS2019-ST1.1-N41O2, 5 p. DOI: 10.3997/22144609. 201902662

[12] Loke, M. Electrical imaging surveys for environmental and engineering studies. A practical guide to 2-D and 3-D surveys. Malaysia, 67 p., 1999.

[13] Griffiths, D. \& Barker, R. Two dimensional resistivity imaging and modeling in areas of complex geology, Journal of Applied Geophysics, vol. 29 (2-3), pp 211-226, 1993. DOI: 10.1016/0926-9851(93)90005-J

[14] Loke, M. A practical guide to RES2DINV ver. 3.4; Rapid 2-D resistivity \& IP inversion using the least-squares method. Geotomo Software, Malaysia., 129 p., 2001.

[15] Daniels, F. \& Alberty, R. Physical chemistry, John Wiley \& Sons, New York, USA, 687 p., 1975.

[16] Keller, G. \& Frischknecht, F. Electrical methods in geophysical prospecting. Pergamon Press, Oxford, UK, 519 p., 1966. 